\title{
Design and test of a novel crawler-type multi-channel air-assisted orchard sprayer
}

\author{
Wei Qiu ${ }^{1 *}$, Xiaolong $\mathrm{Li}^{1}$, Chongchong Lii ${ }^{1}$, Weimin Ding ${ }^{1}$, Xiaolan $\mathrm{Lv}^{2}$, Yande Liu ${ }^{3}$ \\ (1. College of Engineering, Nanjing Agricultural University, Nanjing 210031, China; \\ 2. Jiangsu Academy of Agricultural Sciences, Nanjing 210000, China; \\ 3. Co-Innovation Center of the Intelligent Management and Equipment for Orchard on the Hilly Land in South China, \\ Nanchang 330013, China)
}

\begin{abstract}
In order to solve the problem of poor traveling stability and excessive pesticide application during plant protection operations in hilly orchards, a novel crawler-type multi-channel air-assisted sprayer that is particularly appropriate for hilly orchards was designed in this study. Considering anti-rolling requirements and the orchard environment in hilly areas, this study selected limits for uphill and downhill rolling angles as well as the transverse rolling angle as the evaluation indexes for determining both the layout and parameter settings of the sprayer. According to freely submerged jets and the requirements in plant protection operation, a multi-channel air-assisted system was developed. The test results showed that the anti-rolling performance and the designed air-assisted system were adequate. At $2 \mathrm{~m}$ from the longitudinal center plane of the sprayer, the airflow exhibited wavy distribution patterns under different parameter combinations since the four streams of the airflow were not thoroughly intersected and mixed. At $3 \mathrm{~m}$ from the longitudinal center plane of the sprayer, the jet was ejected at great velocity but underwent rapid attenuation; the airflow velocity in most areas barely satisfied the requirements for plant protection operation. In addition, different air outlet layout schemes led to significant differences in the spatial distribution of the airflow field. Compared with a traditional air-assisted sprayer, using the developed multi-channel air-assisted sprayer enhanced the droplet coverage uniformity by $19.4 \%$, and the mean droplet deposition in the front, middle, and rear of the canopy was enhanced by $32.9 \%, 50.3 \%$, and $78.1 \%$, respectively, while reducing ground deposition and air drift by $26.8 \%$.
\end{abstract}

Keywords: fan, dual-flow-channel, plant protection, air-assisted, test

DOI: $10.25165 /$ j.ijabe.20201306.5362

Citation: Qiu W, Li X L, Li C C, Ding W M, Lv X L, Liu Y D. Design and test of a novel crawler-type multi-channel air-assisted orchard sprayer. Int J Agric \& Biol Eng, 2020; 13(6): 60-67.

\section{Introduction}

Fruit plants are characterized by great variety and population density in China. Currently, most of the fruit plants are cultivated in sloppy, mountainous and hilly areas pattern with low tree canopies and dense population in rigid a furrow pattern.

Traditional plain orchard machinery cannot satisfy the requirements in practical applications in terms of driving stability and trafficability ${ }^{[1,2]}$. As orchard plant protection also face a lot of field issues mainly including excessive pesticide application, pesticide residues and unified prevention and treatment. Therefore, development of mechanized spraying equipment and machines with high operational efficiency applicable to orchards in hilly and uneven field is a real requirement ${ }^{[3-5]}$. Currently, scholars all over the world have reached an extensive consensus on the potential and application prospects of air-assisted pesticide

\section{Received date: 2019-08-28 Accepted date: 2020-04-28}

Biographies: Xiaolong Li, MA. Eng, research interests: pesticide application technology, Email: 578813236@qq.com; Chongchong Li, MA. Eng, research interests: theory and design of agricultural machinery, Email: lichongchong217@qq.com; Weimin Ding, Professor, research interests: agricultural machinery. Email: wmding@njau.edu.cn; Xiaolan Lv, PhD, Professor, research interests: pesticide application technology, Email: 1xlanny@126.com; Yande Liu, PhD, Professor, research interests: Photoelectric detection technology of agricultural products, Email: liuyande@ecjtu.jx.cn.

*Corresponding author: Wei Qiu, PhD, Associate Professor, research interests: pesticide application technology. Mailing address: College of Engineering, Nanjing Agricultural University, Nanjing 210031, China. Tel: +86-2558606570, Email: qiuwei@njau.edu.cn. application techniques and have used it as an important method to enhance yield and reduce pesticide use in orchards ${ }^{[6-9]}$. However, most air-assisted orchard sprayers are equipped with an axial flow fan and adopt an annular spraying mode, and the nozzles are at different distances from the tree canopy ${ }^{[10-13]}$. The nearby droplets may rebound while the distant pesticide probably cannot adhere to the tree canopy ${ }^{[14]}$. As an irregular object, the demands of airflow and spray rate in different canopy diameters were different. The airflow field is generally adjusted by changing the rotational speed of the axial-flow fan and is suggested that the spatial distribution of the flow field should be adjust more precisely ${ }^{[15-17]}$. During the pesticide application in orchard, variability of wind velocity highly affects the shape of the flow field and subsequent spray penetration and losses. The uneven path makes the process more complex.

So, the aims of this study were to 1) analyze the effects of the length-to-width ratio and the location of the center of mass on the sprayer's stability; 2) investigate the multi-channel air-assisted pesticide considering the irregular characteristics of the tree canopy. On the basis of free air jet characteristics and pesticide application technical theory, the positions of the air outlets of the different channels were adjusted so as to form different airflow and droplet distributions in the regions with different canopy diameters and thus achieve precision pesticide application. Accordingly, the difficulties of mechanized operation in hilly and gentle-slope areas can be addressed, and the structure and main parameters of crawler-type multi-channel air-assisted sprayer for orchards were determined, which can provide new ideas and reference for air-assisted pesticide application. 


\section{Materials and methods}

\subsection{Design of crawler-type multi-channel air-assist orchard sprayer}

A novel designed crawler-type multi-channel air-assisted orchard sprayer mainly consists of the multi-channel air-assisted system, the atomizing system, the chassis, the power distribution and the transfer system (Figure 1). The driving system is mainly composed of the engine (type: ZN490, Changchai Co., Ltd.), the gearbox, the transmission shaft, the tensioning wheel and the driving wheel. By manually adjusting the flow of the variable pump, the rotational speed of the hydraulic motor reached the rated value so as to achieve stepless speed variation of the fan (nine blades; diameter: $600 \mathrm{~mm}$ ) within the range of 0-2400 r/min. During operation, the engine was started and part of the power was transmitted to the chassis' travelling system so as to drive the movement of the sprayer, while the rest of the power was transmitted to the hydraulic double-pump (type: 2CBFC-32/16) and hydraulic motors (type of pesticide pump hydraulic motor: BM1-80, Paiyi Hydraulic Machinery Co., Ltd.; type of fan hydraulic motor: A2F12W3P1, Jinxiang Henghai Hydraulic Machinery Co., Ltd) so as to drive the operation of the pesticide pump (type: ZMB480, Jinhua Agricultural Pesticide Machinery Factory) and the fan. The pesticide was delivered from the pesticide tank, through the filter, the pesticide pump and the valve controller to the nozzle (type: NH-101, Taizhou Sunny Agricultural Machinery Co., Ltd.) via the pipes; meanwhile, the airflow was transported to the various airflow arms that were symmetrically arranged on both sides of the sprayer via the hose (Table 1)

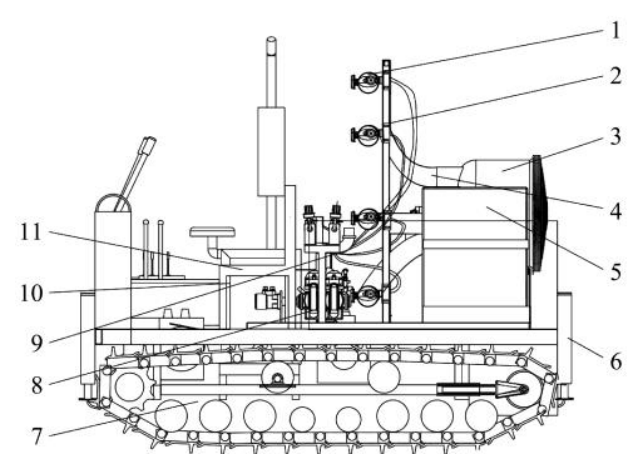

1. Air outlet 2. Airflow support arm 3. Fan 4. Multi-arm guiding device

5. Pesticide tank 6. Supporting leg 7. Crawler chassis 8. Pesticide pump 9. Valve set 10. Engine 11. Cab

Figure 1 Structural diagram of the designed crawler-type multi-channel air-assisted orchard sprayer

Table 1 Key parameters of the designed crawler-type multi-channel air-assisted orchard sprayer

\begin{tabular}{|c|c|c|c|}
\hline Parameter & Value & Parameter & Value \\
\hline $\begin{array}{l}\text { Length } \times \text { Width } \times \text { Height/ } \\
\mathrm{mm}\end{array}$ & $2600 \times 1600 \times 2300$ & Impeller diameter/mm & 600 \\
\hline Power/kW & 34 & $\begin{array}{l}\text { Rotational speed range } \\
\text { of the fan } / \mathrm{m} \cdot \mathrm{s}^{-1}\end{array}$ & $0-2400$ \\
\hline Travelling speed $/ \mathrm{km} \cdot \mathrm{h}^{-1}$ & $0 \sim 7.2$ & \begin{tabular}{|l} 
Outlet airflow \\
velocity $/ \mathrm{m} \cdot \mathrm{s}^{-1}$
\end{tabular} & $0-50$ \\
\hline Unladen weight $/ \mathrm{kg}$ & 1800 & Shape of the air outlet & Rounded \\
\hline $\begin{array}{l}\text { Volume of the pesticide } \\
\operatorname{tank/L}\end{array}$ & 400 & $\begin{array}{l}\text { Shape of the liquid } \\
\text { outlet }\end{array}$ & Tapered \\
\hline $\begin{array}{l}\text { Gauge of the crawler } \\
\text { tracks } / \mathrm{mm}\end{array}$ & 1250 & Spraying height $/ \mathrm{m}$ & $3-4$ \\
\hline $\begin{array}{l}\text { Ground contact length } \\
\text { of track } / \mathrm{mm}\end{array}$ & 1800 & Spraying pressure/MPa & $0-1.5$ \\
\hline Track width/mm & 350 & Flow rate $/ \mathrm{L} \cdot \mathrm{min}^{-1}$ & $1.0-1.2$ \\
\hline
\end{tabular}

\subsection{Theoretical analysis}

2.2.1 Design of the layout and the parameters based on the stability analysis

The design of the sprayer's layout scheme should not only achieve the functions of traveling and air-assisted spraying, but also be optimized in combination with each assembly size and the weight parameters, so as to satisfy the particular requirements of operation in hilly areas. Overall, the present design should obey the following principles: Firstly, the sprayer should cause no damage to the branches and fruit during the operation and the distance between the nozzle and the tree canopy should exceed $500 \mathrm{~mm}$. Secondly, the position of the center of mass should be reasonably located. The distance between the center of mass and the center of the front-thrust wheel should be smaller than $1000 \mathrm{~mm}$, the distance between the center of mass and the longitudinal symmetrical plane should be smaller than $100 \mathrm{~mm}$ and the height of the center of mass should be no greater than $1800 \mathrm{~mm}$. Finally, from reference to Technical Requirements of Operating Safety for Agricultural Machinery-Part 1: Tractor $^{[18]}$, the specific power of the sprayer should be greater than $0.01 \mathrm{~kW} / \mathrm{kg}$.

In combination with the agronomic parameters in a modern orchard plantation (i.e., the line spacing ranges from 4 to $5 \mathrm{~m}$ and the canopy thickness ranges from 1.5 to $2 \mathrm{~m}$ ), the sprayer width was set as $1.6 \mathrm{~m}$, while the gauge, the grounded length and the width of the track were set as $1250 \mathrm{~mm}, 1800 \mathrm{~mm}$ and $350 \mathrm{~mm}$, respectively. Meanwhile, by considering the assembly size and mass parameters, the plane layout was designed, as shown in Figure 2. Due to the great number of parts, the spatial position of the center of mass was hard to calculate, and a 3D model was established by setting the mass parameters of the parts so as to simulate the center of mass and conduct a preliminary estimation. According to the virtual prototype, the sprayer's weight was $2200 \mathrm{~kg}$, the distance between the center of mass and the center of the front thrust wheel was $926.4 \mathrm{~mm}$, the distance between the center of mass and the longitudinal symmetrical plane was $62.8 \mathrm{~mm}$ and the height of the center of mass was $1597.6 \mathrm{~mm}$, i.e., $M_{m}=2200 \mathrm{~kg}, x_{m}=926.4 \mathrm{~mm}, y_{m}=-62.8 \mathrm{~mm}$ and $h_{m}=1597.6 \mathrm{~mm}$.

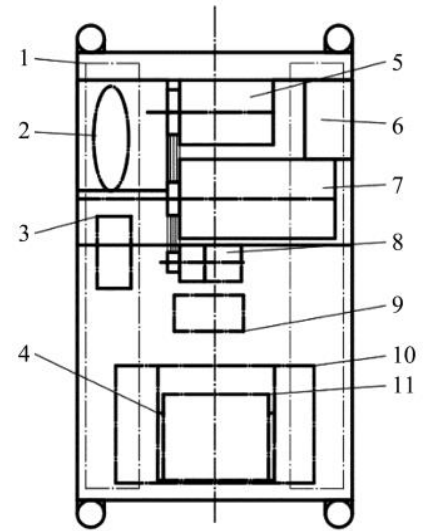

\begin{tabular}{|c|c|c|}
\hline Number & Size $/ \mathrm{mm}$ & Quality $/ \mathrm{kg}$ \\
\hline 1 & $2285 \times 350 \times 450$ & 415 \\
\hline 2 & $430 \times 350 \times 810$ & 45 \\
\hline 3 & $270 \times 150 \times 240$ & 40 \\
\hline 4 & $700 \times 500 \times 400$ & 195 \\
\hline 5 & $960 \times 450 \times 350$ & 205 \\
\hline 6 & $700 \times 310 \times 240$ & 50 \\
\hline 7 & $800 \times 450 \times 650$ & 285 \\
\hline 8 & $450 \times 300 \times 300$ & 115 \\
\hline 9 & $300 \times 200 \times 200$ & 45 \\
\hline 10 & $650 \times 450 \times 650$ & 405 \\
\hline 11 & $880 \times 585 \times 755$ & 400 \\
\hline
\end{tabular}

1. Track 2. Cab 3. Pesticide pump 4. Hydraulic oil tank 5. Gearbox 6. Oil tank 7. Engine 8. Clutch and hydraulic pump 9. Battery 10. Fan 11. Pesticide tank

Figure 2 Planar layout of the designed crawler-type multi-channel air-assisted orchard sprayer

2.2.2 Determination of the air outlet parameters based on the jet characteristics

When designing the parameters of an air-assisted sprayer using traditional methods, it is generally assumed that airflow rates through the cross-sections remain constant. According to the substitution principle, the airflow rate was calculated, and then the 
outlet velocity of the fan was calculated based on the end velocity, thereby calculating the outlet area of the fan. However, multi-channel air-assisted pesticide applications adopt an orifice jet for the air supply, and the ejected airflow exhibits high velocity at the outlet with rapid attenuation. In addition, the fan was connected with multi-channel hoses, and a lot of elbows are used, which results in great local and linear losses. Therefore, energy attenuation that occurs when the gas passes through the hoses and the variation rules of the circular-section jet velocity along the spraying range should be taken into account. If the minimum final velocity is no smaller than $11 \mathrm{~m} / \mathrm{s}^{[19]}$, the airflow velocity at any point on the jet cross-section to the tree canopy will exceed $11 \mathrm{~m} / \mathrm{s}$. Due to the existence of a lot of air outlets, the airflow velocity was lowest on the boundary between two jets, i.e., when $r=L_{f}-S \tan \theta$ (where $L_{f}$ denotes the spacing between the air outlets), and the airflow velocity $V$ reached a minimum. Since the air outlets were round and freely submerged jets were ejected, the jet cross-section was expanded along the spraying range, as shown in Figure 3 , and the jet velocity along the axis should satisfy the following equations:

$$
\begin{aligned}
& V=V_{m}\left[1-\left(\frac{r_{f}}{R_{1}}\right)^{1.5}\right]^{2} \geq 7 \mathrm{~m} / \mathrm{s} \\
& 0.966 V_{0}=\left(\frac{\alpha S}{R_{0}}+0.294\right) V_{m}
\end{aligned}
$$

where, $V_{m}$ denotes the jet velocity along the axis, with units of $\mathrm{m} / \mathrm{s}$; $V_{0}$ denotes the mean airflow velocity at the air outlet, with units of $\mathrm{m} / \mathrm{s} ; \alpha$ denotes an experimental coefficient which mainly depends on the structure of the air outlet, the uniformity of the airflow velocity distribution and the disturbance at the air outlet. $S$ denotes the distance between the air outlet and the tree canopy, with units of m. $\quad R_{0}$ and $R_{1}$ denote the radii of the air outlet and the cross-section $\left(R_{1}=S \tan \theta\right)$, with units of $\mathrm{m}$. denotes the velocity of any point $\mathrm{M}$ on the jet cross-section, with units of $\mathrm{m} / \mathrm{s}$. $r_{f}$ denotes the radial distance from the jet axis to any point, with units of $\mathrm{m}$.

The values of the related parameters can be set as follows: $V \geq 11 \mathrm{~m} / \mathrm{s}, V_{0}=22.0 \mathrm{~m} / \mathrm{s}, S=0.7 \mathrm{~m}$ and $L_{f}=0.3 \mathrm{~m}$; since the air outlets were cylindrical tubes, $\alpha=0.1129$ and $\theta=21^{\circ}$. By combining Figure (4) and Figure (5), the radius of the air outlet, $R_{0}$, should be no smaller than $0.049 \mathrm{~m}$.

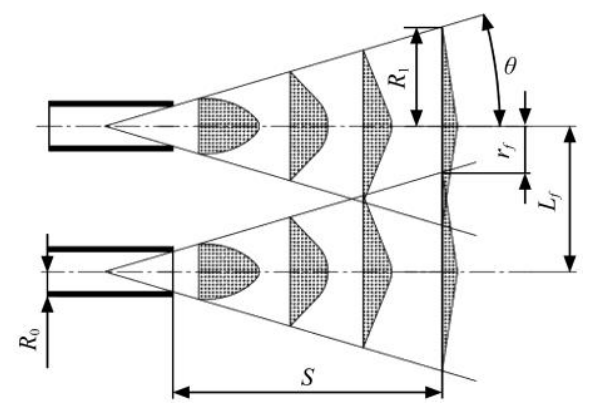

Figure 3 Illustration of the freely submerged jets

Due to different canopy shapes, the spacing between the air outlets can be adjusted in accordance with the actual canopy shape, so as to ensure differentiation of the spatial distributions of the airflow field and the mist field. Accordingly, sufficient jets can be coincident in the large canopy region.

\subsection{Test scheme}

2.3.1 Measurement of the center of mass and the static rolling test

The sprayer was developed in accordance with the above-described layout. In order to ensure that the uphill and downhill rolling angle limits and the transverse rolling angle limit under the actual center-of-mass condition fit well with the results under the simulated center-of-mass condition, the spatial position of the center of mass of the sprayer was measured from reference to Agricultural Tractors-Test Procedures-Part 15: Center of Gravity $^{[20]}$. Four weighing platforms were placed on a level ground, and supporting frames were arranged above the weighing platforms. The sprayer was hoisted onto the weighing platform, and the pressures at the four supporting points were read to calculate the center of mass based on the principle of moments. As shown in Figure 4, the sprayer was suspended on one side while the other side was placed on the weighing platform.
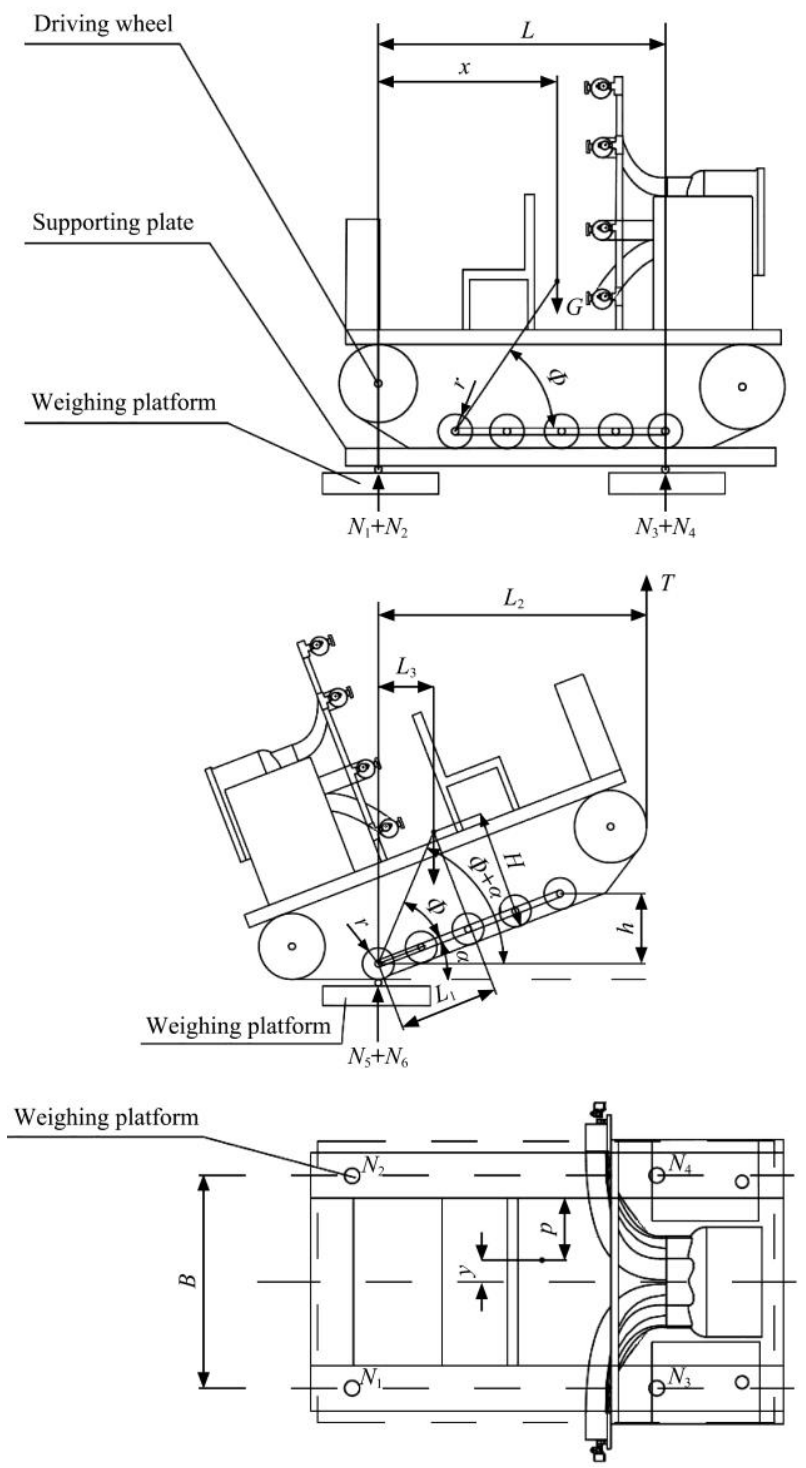

Figure 4 Illustration of the principle of the center-of-mass measurement

According to the angular transformation and moment balance, the position of the center of mass of the developed sprayer could be calculated as:

$$
\begin{gathered}
x=\frac{\left(N_{3}+N_{4}\right) \times L}{G} \\
y=\frac{B}{2}-p \\
H=r+L_{1} \times \tan \Phi \\
p=\frac{\left(N_{1}+N_{3}\right) \times B}{G}
\end{gathered}
$$




$$
\begin{gathered}
\tan \Phi=\frac{\cos \alpha-\frac{L_{3}}{L_{1}}}{\sin \alpha} \\
L_{3}=\frac{T \times L_{2}}{G} \\
T=G-\left(N_{5}+N_{6}\right)
\end{gathered}
$$

where, $L$ is the horizontal distance from the center of the driving wheel to the rear thrust wheel, $\mathrm{m} ; B$ is the trail gauge of the sprayer, $\mathrm{m} ; x$ and $y$ are the longitudinal and transverse deviations of the center of mass, $\mathrm{m} ; p$ is the distance from the center of mass to the center line of the caterpillar track, $\mathrm{m} ; L_{2}$ is the horizontal distance between the lifting rope and the rear thrust wheel, $\mathrm{m} ; T$ is the tension of the steel rope of the hoisting device, $\mathrm{N} ; G$ is the sprayer's weight, $\mathrm{N} ; \alpha$ is the angle between the caterpillar base and the horizontal surface, rad; $r$ is the radius of the thrust wheel, $\mathrm{m} ; \Phi$ is the intersecting angle between the line connecting the center of mass and the center of the front thrust wheel and the line connecting the center of the front thrust wheel and the parallel line of the caterpillar plane, rad.

Based on the measured position of the center of mass of the sprayer, the uphill and downhill rolling angle limits and the transverse rolling angle limit of the sprayer, the mechanical analysis model was established as below:

$$
\begin{gathered}
\Phi_{\text {lim }}=\arctan \frac{L_{0}-x}{h} \geq 20^{\circ} \\
\beta_{\text {lim }}=\arctan \frac{x}{h} \geq 20^{\circ} \\
\gamma_{\text {lim }}=\arctan \frac{0.5(B+b)-y}{h} \geq 20^{\circ}
\end{gathered}
$$

where, $\Phi_{\text {lim }}$ and $\beta_{\text {lim }}$ are the uphill and downhill rolling angle limits, respectively; $\gamma_{l i m}$ is the transverse rolling angle limit; $B$ denotes the track gauge, mm; $b$ is the track width, $\mathrm{mm} ; L_{0}$ is the grounded length of the track, mm.

Meanwhile, to verify the actual rolling performance, the developed sprayer was driven to the tilting test platform, which was fixed by at least two safety ropes so as to avoid rolling or any significant slippage of the sprayer. By slowly starting the test platform, whether the sprayer moved or not was observed and the angle of the test platform was recorded.

2.3.2 Test of the airflow and mist field distribution

The present experiment was performed to examine the effect of the spacing layout of the air outlets on the formation of the airflow and mist field. According to the characteristics of a spindle-shaped canopy of low and dense plants (with a canopy height of 1.8-2.2 m, a canopy diameter of 1.5-2.0 m and a trunk height of $0.5 \mathrm{~m}$ ), three different combinations of the positions of the air outlets were designed (Table 2), and therefore, the spacing between the air outlets could be adjusted so as to achieve different distributions of the airflow and mist. When the rotational speed of the fan was set as $1600 \mathrm{r} / \mathrm{min}$, the measured airflow velocity at the air outlet was $22-25 \mathrm{~m} / \mathrm{s}$. In the parameter combination 1 , four air outlets were arranged uniformly. According to the second and the parameter combinations 3, by taking the spindle-shaped canopy structure into account, the spacing between the middle two air outlets was narrowed so that more spray flow could be sprayed onto the large-canopy-diameter area. According to an industrial standard such as Operation Quality for Air-Assisted Orchard Sprayer ${ }^{[21]}$, the horizontal distance from the sprayer's longitudinal central plane, denoted as $L q$, was set as $2 \mathrm{~m}, 2.5 \mathrm{~m}$ and $3 \mathrm{~m}$, respectively, and then the airflow velocities at different sampling points with a vertical height range of 0.5-3 $\mathrm{m}$ was measured. The sampling points were arranged at a spacing of $0.1 \mathrm{~m}$ in the vertical direction. Meanwhile, the spatial distributions of the droplets at $2 \mathrm{~m}, 2.5 \mathrm{~m}$ and $3 \mathrm{~m}$ away from the longitudinal center planes (corresponding to different values of $L w$ ) were measured by the droplets vertical distributor ${ }^{[22]}$, as shown in Figure 5. The droplets vertical distributor consists of 140 stainless lamellae spacing $2.2 \mathrm{~cm}$; the interception area is $5.8 \mathrm{~m}^{2}$.

Table 2 Arrangement of the positions of the air outlets

\begin{tabular}{ccccc}
\hline Positions of the air outlets & $L_{f 1}$ & $L_{f 2}$ & $L_{f 3}$ & $L_{g}$ \\
\hline Combination 1 & 0.3 & 0.3 & 0.3 & 0.9 \\
Combination 2 & 0.35 & 0.2 & 0.35 & 0.9 \\
Combination 3 & 0.375 & 0.15 & 0.375 & 0.9 \\
\hline
\end{tabular}

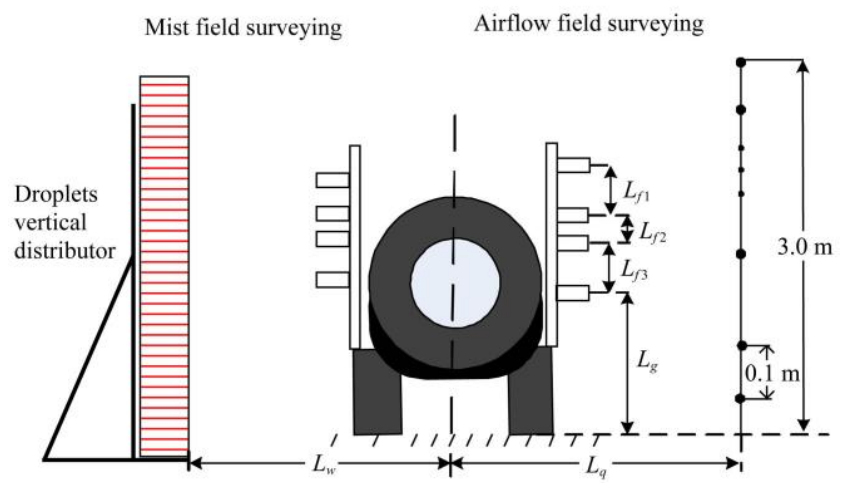

Figure 5 Arrangement of flow field measurement

\subsubsection{Contrast test}

In order to clarify the settlement and distribution performances of the droplets from the multi-channel sprayer, this study has laid emphasis on the settlement and coverage conditions of the droplets in the regions with different canopy diameters and in the canopy, respectively. The experimental results were compared with the performance of traditional diffused air-assisted sprayer $(3 \mathrm{WZ}-700)^{[23]}$, as shown in the results in Figure 6 . Two air-assisted sprayers, with a power of $28 \mathrm{~kW}$ and $34 \mathrm{~kW}$, respectively, were used for modern orchards with a low and dense plantation. With regard to the detailed parameters, the spraying pressure was set as $1 \mathrm{MPa}$, the airflow velocity at the air outlet of the fan was set as $22.0 \mathrm{~m} / \mathrm{s}$ and the operating speed was $1 \mathrm{~m} / \mathrm{s}$. In the present test, the plant canopy height and diameter were set as $2 \mathrm{~m}$ and $1.8 \mathrm{~m}$, respectively, and the row spacing was $4 \mathrm{~m}$. According to the test results and the operation objects as described in Section 2.3.2, the combination 2 of the positions of the air outlets were selected, and the longitudinal center plane was $2.5 \mathrm{~m}$ from the trunk.

This study used the coverage uniformity (CU) of the droplets as the index to evaluate the uniformity of the pesticide application of the sprayer. The uniformity was calculated according to the principle of variance calculation. The settlement of the droplets in the canopy was used to evaluate the sprayer's penetrability. The spraying operation was conducted on 3 trees and a Ponceau $2 \mathrm{R}$ water solution with a mass fraction of $5 \%$ was sprayed. Paper cards (7.6 $\mathrm{cm} \times 7.6 \mathrm{~cm}$; Shanghai $\mathrm{M} \& \mathrm{G}$ Stationery Inc.) were labeled and placed at each of the sampling point to receive the Ponceau 2R water solution. After spraying, these paper cards were scanned into images with an MRS-3200PU2 scanner (Shanghai Microtek Technology Co., Ltd.) in the laboratory, and these images were processed to obtain droplet coverage estimates by image processing technology. Then paper cards were shredded 
into an individual beaker with $25 \mathrm{~mL}$ distilled water, allowed to soak under agitation for $20 \mathrm{~min}$ allowing the Ponceau $2 \mathrm{R}$ to dissolve into the water. The absorbance of the Ponceau 2R solution was measured with a $722 \mathrm{~N}$ visible spectrophotometer (Shanghai Tianpu Instrument Co., Ltd.). The spray deposition $a$ (in $\mu \mathrm{g}$ ) can be calculated using Equation (16)

$$
a=\frac{\delta V}{K}
$$

where, $\delta$ is the absorbance of the Ponceau $2 \mathrm{R}$ solution; $V$ is the volume of added water expressed in $\mathrm{mL}$ (here, $25 \mathrm{~mL}$ ); and $K$ is the absorbance ratio coefficient (here, 0.038).

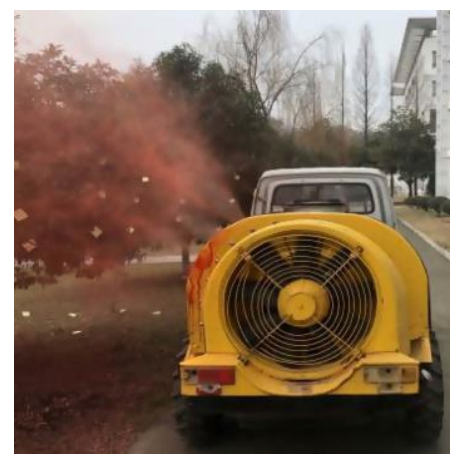

a. 3WZ-700 air-assisted sprayer;

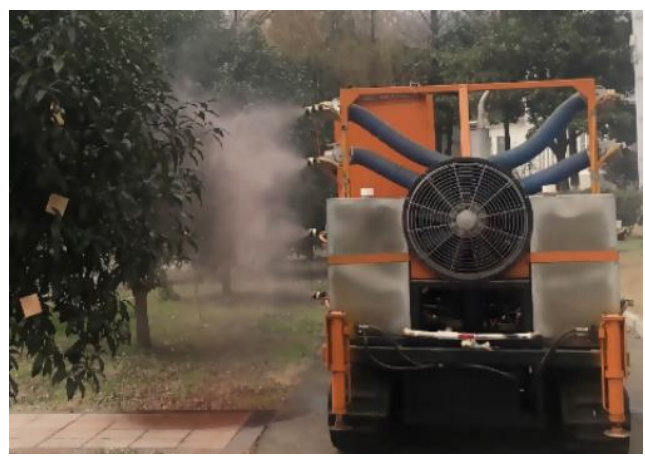

b. Crawler-type multi-channel air-assisted sprayer

Figure 6 Two different sprayer prototypes used in the present contrast test

According to the canopy shape and degree of density, three layers were divided in the vertical direction, namely, the upper layer, the middle layer and the lower layer. In each layer, the matts-type sampling points were arranged at the same interval by using the trunk as the center point. The canopy was divided into three parts in the spray direction, namely the front, the center and the rear, respectively. Meanwhile, as shown in Figure 7, the drift lines and the rods were arranged on the ground and in the air to measure the drift of the sprayed pesticide. At each sampling point paper cards were pasted on both sides to measure the droplet coverage and the settlement of the droplets on the leaves. The coverage uniformity of the droplets was calculated according to the following Equation (17):

$$
C U=100\left(1-\frac{\sum_{i=1}^{N}\left|x_{i}-\bar{x}\right|}{N x}\right)
$$

where, $x_{i}$ denotes the $i$-th measured coverage ratio; $\bar{x}$ denotes the mean value and $N$ is the number of measuring points.

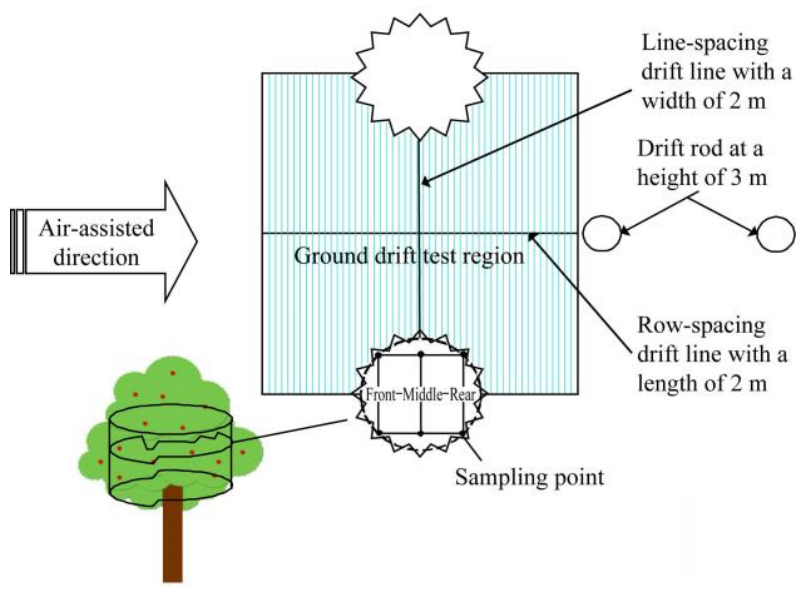

Figure 7 Arrangement of the sampling points in spraying test

\section{Result and discussion}

\subsection{Analysis of the sprayer's static rolling performance}

The atomization quality and the pressure on the four supporting points were also measured and are presented in Table 3 and Table 4. According to Equations (1)-(6), the actual position of the center of mass was calculated as: $x_{z}=906.1 \mathrm{~mm}, y_{z}=$ $-58.45 \mathrm{~mm}$ and $h_{z}=1702.0 \mathrm{~mm}$, which basically agreed with the simulated results from the established 3D model. By substituting the simulated and actual position parameters of the center of mass into Equations (1)-(3), $\Phi_{\text {lim }}, \beta_{\text {lim }}$ and $\gamma_{\text {lim }}$ were calculate (Table 5). Meanwhile, the static rolling test was performed on the sprayer, as shown in Figure 8. The rolling test results showed that the static rolling angles of the developed sprayer all exceeded $20^{\circ}$. The theoretical results showed good consistency with the test data, suggesting that the design requirements can be satisfied.

Table 3 Measured horizontal positions of the center of mass

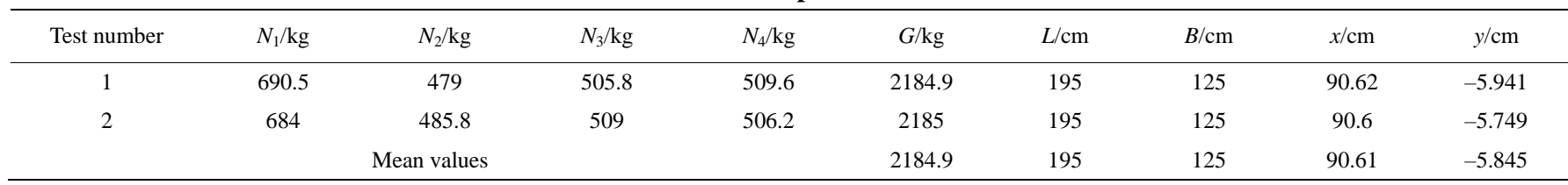

Table 4 Measured heights of the center of mass

\begin{tabular}{ccccccccccc}
\hline $\begin{array}{c}\text { Lifting } \\
\text { height/cm }\end{array}$ & $\begin{array}{c}\text { Measured } \\
\text { data }\end{array}$ & $N_{5}$ & $N_{6}$ & $N_{5}+N_{6}$ & $T / \mathrm{kg}$ & $a$ & $L_{1}$ & $\begin{array}{c}L_{2} \\
r / \mathrm{cm}\end{array} \begin{array}{c}\text { Height of the center } \\
\text { of mass/cm }\end{array}$ & $\begin{array}{c}\text { Mean height of the } \\
\text { center of mass/cm }\end{array}$ \\
\hline$h_{z 1}$ & 22.5 & 744.8 & 679 & 1423.8 & 761.1 & 9.9 & 102 & 198 & 192 \\
$h_{z 2}$ & 30 & 750 & 682.2 & 1432.2 & 752.7 & 12.3 & 102 & 192 & 9 \\
$h_{z 3}$ & 41 & 771.8 & 688.4 & 1460.2 & 724.7 & 15 & 102 & 185 & 170.2 \\
\hline
\end{tabular}

\begin{tabular}{|c|c|c|c|c|c|c|c|}
\hline & $x / \mathrm{mm}$ & $y / \mathrm{mm}$ & $h / \mathrm{mm}$ & $\Phi_{\mathrm{lim}} /\left(^{\circ}\right)$ & $\beta_{\lim } /\left(^{\circ}\right)$ & $\gamma_{\text {lim }} /\left(^{\circ}\right)$ & $M / \mathrm{kg}$ \\
\hline Simulated values & 926.4 & 62.8 & 1597.6 & 28.7 & 30.1 & 28.4 & 2200 \\
\hline Measured values & 906.1 & -58.45 & 1702.0 & 27.7 & 28.0 & 23.5 & 2185 \\
\hline
\end{tabular}

Table 5 Simulated and measured uphill and downhill rolling angle limits and the transverse rolling angle limit 


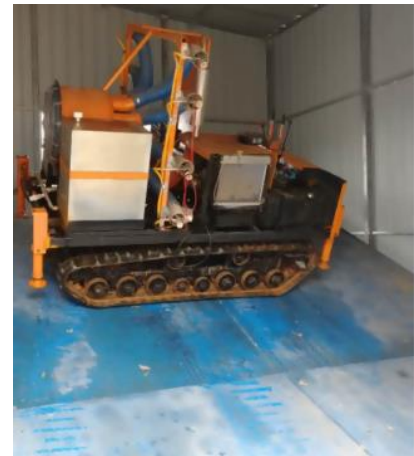

a. Transverse slope-standing process

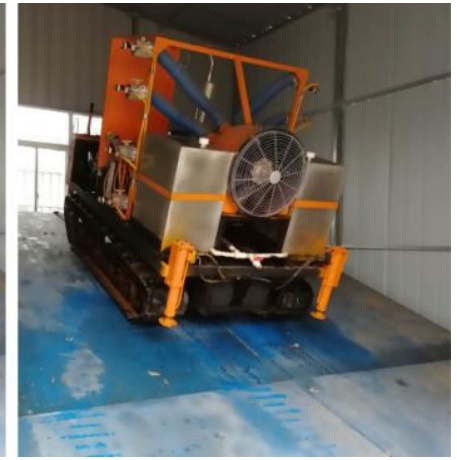

b. Upper slope-standing process
Figure 8 Static rolling test

\subsection{Distribution tests of the flow field}

The multi-channel spraying should satisfy the following conditions: (1) multiple streams of airflow that are already coincident when they arrive at the canopy, (2) the airflow should move at a certain velocity so that it can carry the droplets to penetrate the canopy ${ }^{[24]}$, and (3) the airflow and mist amounts were different in the regions with different canopy diameters. Based on the principle above, the rulers of the airflow field were discussed below. As shown in Figure 9, since four streams of airflow were not completely overlapped and mixed at $2 \mathrm{~m}$ from the longitudinal center plane of the sprayer, the airflow under different parameter combinations exhibited wavy distribution patterns. At $2.5 \mathrm{~m}$ from the longitudinal center plane of the sprayer, and because of the uniform arrangement of the air outlets using the parameter combination 1, the airflow in the middle section of the canopy (at a height of 1.0-1.8 $\mathrm{m}$ above the ground) was not remarkably enhanced and still exhibited a wavy distribution pattern. Using the parameter combination 3, due to a smaller spacing of the middle two air outlets, a stream of strong airflow was produced in the middle section of the canopy. However, on account of the greater spacing between the other air outlets, this still existed in the airflow distribution pattern, i.e., the airflow still exhibited a wavy distribution pattern. At $3.0 \mathrm{~m}$ from the longitudinal plane of the sprayer, the airflow velocity distribution patterns under the parameter combinations 2 and 3 were spindle-shaped. However, with the increase of the distance, the airflow velocity dropped particularly in the non-middle sections. At $2.5 \mathrm{~m}$ from the longitudinal plane of the sprayer, the airflow distributions in the vertical planes using the parameter combination 2 were similar in shape to a spindle-shaped tree, and also had enough velocity in the non-middle sections.
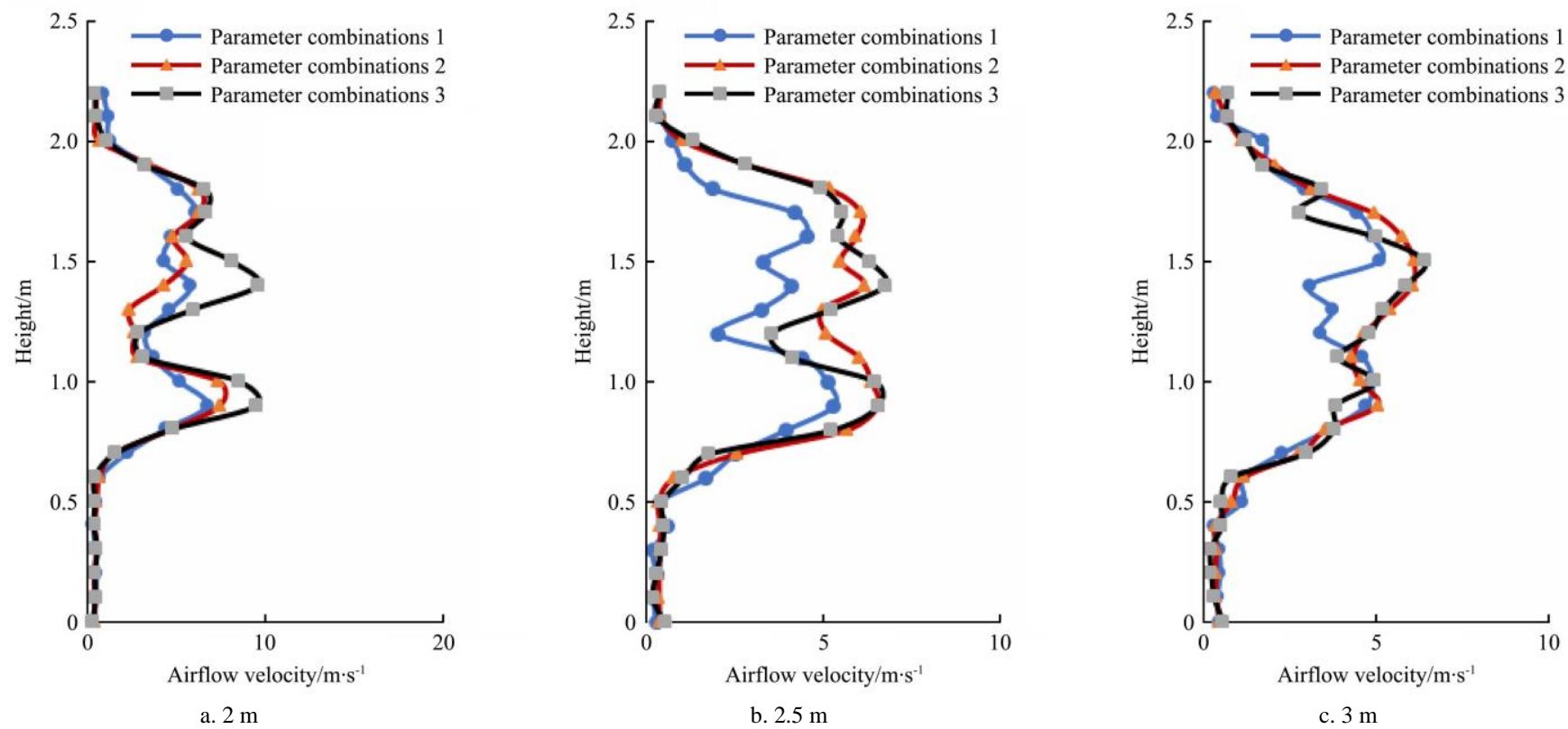

Figure 9 Airflow distribution at different distances from the longitudinal center plane of the sprayer

Considering the diffusivity of the mist in the flow field, the spray amount exhibited no significant difference under the different combinations of parameters compared with the airflow distribution. The spray volumes in the middle section of the canopy (at a height of 1.0-1.8 m) under the parameter combinations 2 and 3 were enhanced to different degrees compared with the volume using the parameter combination 1, as shown in Figure 10.

\subsection{Droplet deposition and drift rules in the canopy using two different types of sprayers}

Compared with the condition using the traditional diffused air-assisted sprayer (3WZ-700), the mean coverage ratio and uniformity of the droplet using the crawler-type multi-channel air-assisted sprayer were enhanced by $29.2 \%$ and $19.4 \%$, respectively, as shown in Figure 11, Using two different types of sprayers, the droplets decreased gradually in the canopy along the direction of the air supply. The mean droplet depositions in the front, middle and rear of the canopy, using the developed crawler-type multi-channel air-assisted sprayer, were 32.9\%, 50.3\% and $78.1 \%$ higher respectively than the values from the traditional diffused sprayer, accompanied with a reduction in ground deposition and air drift by $23.2 \%$.

The droplet coverage uniformity, penetrability and directed anti-drift performance could be remarkably enhanced when using the developed crawler-type multi-channel air-assisted sprayer. Due to the airflow coming out of the pipe, it has good directivity and strong penetrating ability, so the drift decreases and the internal deposition increases ${ }^{[25]}$. However, it should also be noted that the injection area from the pipeline is relatively small, so the gap between the adjacent air outlets should be adjusted to prevent the canopy from not being fully covered ${ }^{[23,24]}$. Due to the fast attenuation of the airflow velocity, the airflow velocity to reach the canopy should be measured. 

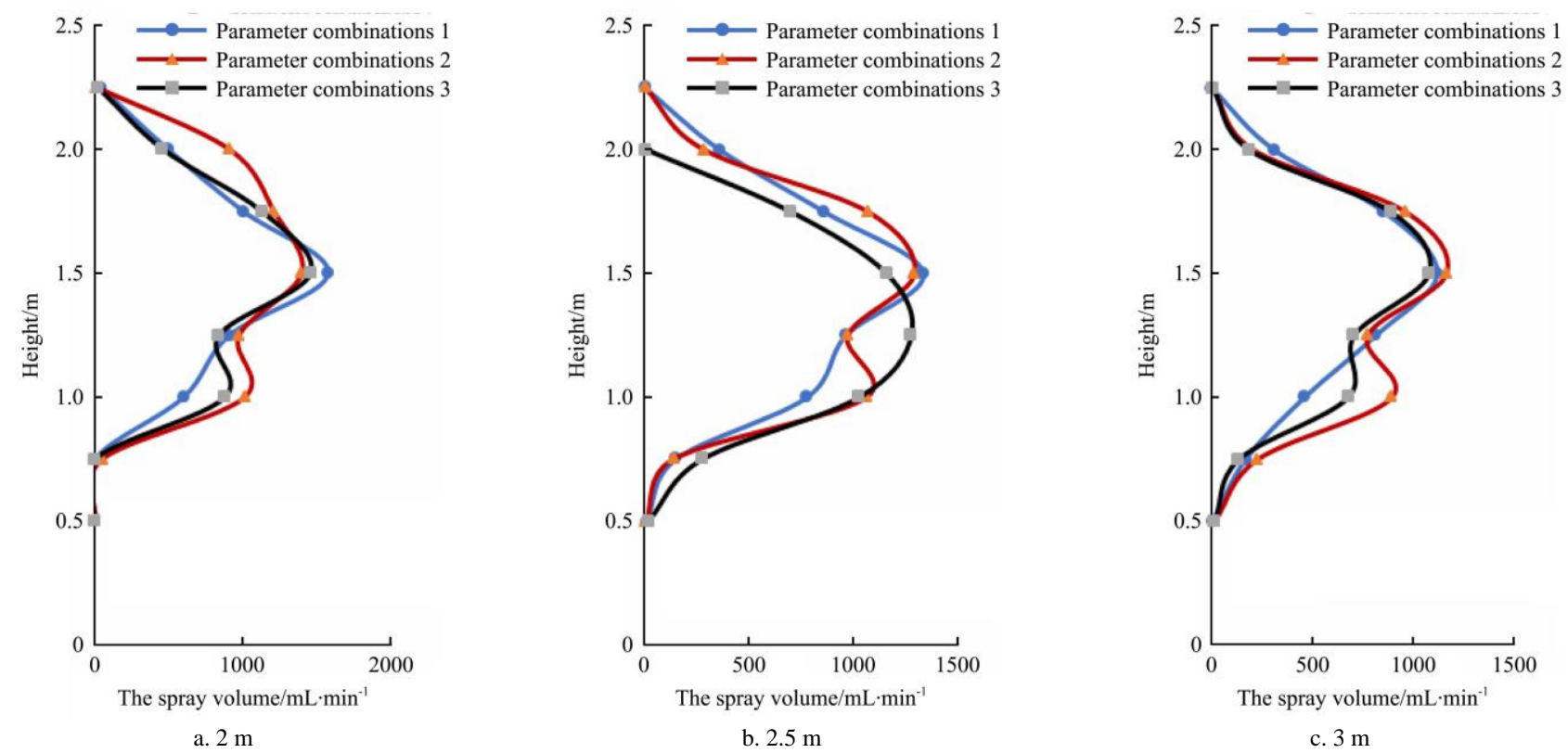

Figure 10 Amount distribution at different distances from the longitudinal center plane of the implement
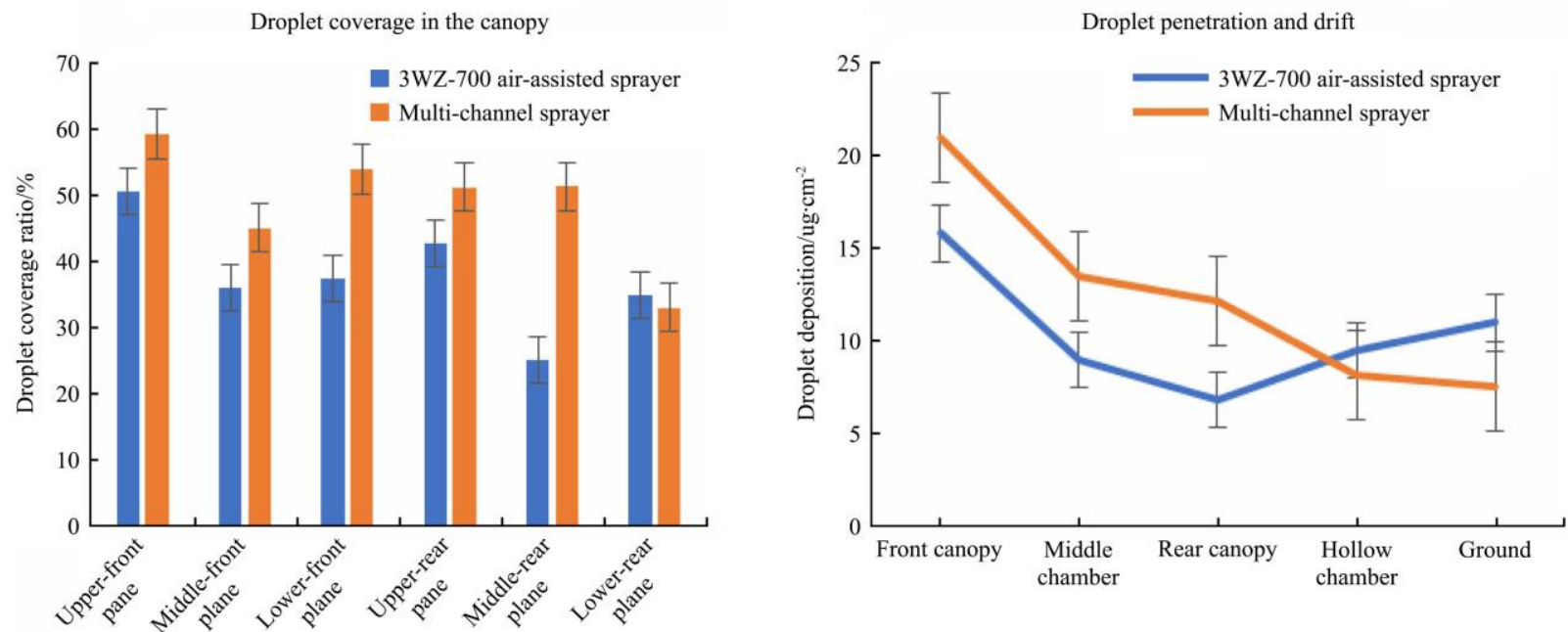

Figure 11 Coverage, penetrability and drifting performance of the droplets formed in the canopy (Error bars represent standard deviations of means)

\section{Conclusions}

1) According to the anti-rolling requirement in hilly areas and the orchard gardening environment, a crawler-type multi-channel air-assisted sprayer with high stability was designed. The ratio of the trail gauge to the grounded length was 0.7 and the static rolling angles all exceeded $20^{\circ}$.

2) At $2.5 \mathrm{~m}$ from the longitudinal center plane of the sprayer, the airflow and droplet exhibited similar spindle-shaped distribution patterns to the fruit trees around the air outlets under the appropriate parameter settings. It is suggested that the distance between the target tree trunk and the fan center should be no smaller than $2.5 \mathrm{~m}$ during the operation of the developed sprayer.

3) In contrast with the traditional diffused-type air-assisted sprayer, the coverage ratio of the droplets, mean droplet deposition in the front, middle and rear of the canopy were enhanced by $19.4 \%, 32.9 \%, 50.3 \%$ and $78.1 \%$, respectively, while droplet deposition on the ground and air drift were reduced by $23.2 \%$ when using the developed crawler-type multi-channel air-assisted sprayer.

\section{Acknowledgements}

This project was supported by the National Natural Science Foundation of China (Grant No. 51805271), Jiangsu Agricultural Science and Technology Innovation Fund (CX181007), and Fundamental Research Funds for the Central Universities (KYYJ201805).

\section{[References]}

[1] Zhang J F, Li J Y, Zhang Y L, Li S J, Meng L. Design of remote control monorail transporter for mountainous orchard. Transactions of the CSAM 2012; 43(2): 90-95. (in Chinese)

[2] Chen K. The development of an automatic orchard spraying machine in hilly and mountainous region. PhD dissertation. Chongqing: A Master Dissertation from Southwest University, 2017; 14 p.

[3] Zhang X H, Jiang Z Y, Fan G Q, Cao L L. Self-Propelled Crawler Directional Air-Blowing Orchard Sprayer. Transactions of the CSAM, 2014; 45(8): 117-122, 247. (in Chinese)

[4] Zhou H Y, Yang B N, Yan H R, Yang X J. Application status and development prospects of effective plant protection machinery. Agricultural Engineering, 2014; 4(6): 4-6. (in Chinese)

[5] Wang W Z, Hong T S. Review of the pesticide precision orchard spraying technologies. Transactions of the CSAE, 2004; 20(6): 98-101. (in Chinese) 
[6] Duga A T, Ruysen K, Dekeyser D, Nuyttens D, Bylemans D, Nicolai B M, et al. Spray deposition profiles in pome fruit trees: Effects of sprayer design, training system and tree canopy characteristics. Crop Prot., 2015; 67: 200-213

[7] Hołownicki R, Doruchowski G, Swiechowski W, Godyn A, Konopacki P J. Variable air assistance system for orchard sprayers; concept, design and preliminary testing. Biosystems Engineering, 2017; 163: 134-139.

[8] Li L L, He X K, Song J L, Liu Y J, Zeng A J, Liu Y, et al. Design and experiment of variable rate orchard sprayer based on laser scanning sensor. Int J Agric \& Biol Eng, 2018; 11(1): 101-108

[9] Zhang P, Deng L, Lyu Q, He S L, Yi S L, Liu Y D, et al. Effects of citrus tree-shape and spraying height of small unmanned aerial vehicle on droplet distribution. Int J Agric \& Biol Eng, 2016; 9(4): 45-52.

[10] Hong S W, Zhao L Y, Zhu H P. CFD simulation of pesticide spray from air-assisted sprayers in an apple orchard: Tree deposition and off-target losses. Atmospheric Environment, 2018; 175: 109-119.

[11] Kira O, Dubowski Y, Linker R. ScienceDirect In-situ open path FTIR measurements of the vertical profile of spray drift from air-assisted sprayers. Biosystems Engineering, 2018; 169: 32-41.

[12] Qiu W, Sun C D, Lv X L, Ding W M, Feng X B. Effect of air-assisted spray application rate on spray droplet deposition distribution on fruit tree canopies. Applied engineering in Agriculture, 2016; 32(6): 739-749.

[13] Zhou L F, Zhang L, Xue X Y, Ding W M, Sun Z, Zhou Q Q. Design and experiment of 3WQ-400 double air-assisted electrostatic orchard sprayer. Transactions of the CSAE, 2016; 32(16): 45-53. (in Chinese)

[14] Lv X L, Zhang M N, Chang Y H, Lei X H, Yang Q S. Influence of deflector angles for orchard air-assisted sprayer on 3D airflow distribution. Transactions of the CSAE, 2017; 33(15): 81-87. (in Chinese)

[15] Tang Y, Hou C J, Luo S M, Lin J T, Yang Z, Huang W F. Effects of operation height and tree shape on droplet deposition in citrus trees using an unmanned aerial vehicle. Computers and Electronics in Agriculture, 2018; $148: 1-7$

[16] Zhai C Y, Xu S, Long J, Li H Z, Zhang B, Zhu R X, et al. Optimization design of orchard air-assisted sprayer and mathematical model for spray height control. Journal of Northwest A\&F University (Nat. Sci. Ed.),
2018; 46(9): 148-154. (in Chinese)

[17] Li L L, He X K, Song J L, Liu Y, Wang Z C, Li J Y, et al. Comparative experiment on profile variable rate spray and conventional air-assisted spray in orchards. Transactions of the CSAE, 2017; 33(16): 56-63. (in Chinese)

[18] National Agricultural Machinery Standardization Technical Committee. GB 16151.1-2008. Technical requirements of operating safety for agricultural machinery-Part 1: Tractor, 2008. (in Chinese)

[19] Dai F F. Selection and calculation of the blowing rate of air-assisted sprayers. Plant Protection, 2008; 34(6): 124-127.

[20] National Tractor Standardization Technical Committee. GB/T 3871.15-2006. Agricultural Tractors-Test Procedures-Part 15: Center of Gravity, 2006. (in Chinese)

[21] National Agricultural Machinery Standardization Technical Committee NY/T 992-2006. Operation Quality for Air-Assisted Orchard Sprayer, 2006. (in Chinese)

[22] Biocca M, Gallo P. Comparison between horizontal and vertical lamellate patternators for air-blast sprayers. The Open Agriculture Journal, 2014 8(1): 12-17.

[23] Qiu W, Ding W M, Wang X C, Gong Y, Zhang X X, Lv X L. 3WZ-700 self-propelled air-blowing orchard sprayer. Transactions of the CSAM, 2012; 43(4): 26-30, 44. (in Chinese)

[24] Derksen R C, Krause C R, Losely K, Brazee R D, Fox R D, Zhu H, et al A specially designed air-assisted sprayer to improve spray penetration and air jet velocity distribution inside dense nursery crops. Transactions of the ASABE, 2006; 49(5): 1285-1294.

[25] Wu Y S, Cheng X, Ding W M, Xiao M H, Gu J B, Qiu W. Structural optimization of the rear arc cover of a multi-channel air-assisted sprayer. International Agricultural Engineering Journal, 2018; 27(2): 73-81.

[26] Chao X Y, Chen S, Qiu W, Gu J B, Lv X L, Li H, et al. Simulation and validation of the air flow generated by a multi-channel air-assisted sprayer. IEEE access, 2019; 7: 94848-94857.

[27] Hołownicki R, Doruchowski G, Świechowski W, Godyń A, Konopacki P J. Variable air assistance system for orchard sprayers; concept, design and preliminary testing. Biosystems Engineering, 2017; 163: 134-149. 